\title{
Uncommon and Dangerous Foreign Body in an Infant's Larynx: An Interesting Presentation
}

\author{
Vinit K Sharma ${ }^{1}$, Amit K Rana², Rohit Sharma ${ }^{3}$
}

\begin{abstract}
Laryngeal foreign bodies are less common than bronchial foreign bodies. They pose a challenge sometimes because of subdued symptoms and therefore resulting in late diagnosis. Removal of such foreign bodies is challenging especially in infants, and one needs to be prepared for all sorts of variations on the OT table. We present an interesting case where an 8-month-old infant presented with a toe ring inside her larynx, which was peculiarly causing symptoms of both respiratory obstruction and pooling of saliva. The top flat part of the toe ring was seen to be covering the posterior half of the glottis and its ring was stuck inside the cricopharynx. This was a case of a single foreign body obstructing both the tracts at the same time. It was removed carefully with direct laryngoscopy and the patient recovered uneventfully after the procedure.
\end{abstract} Keywords: Airway, Bronchoscopy, Esophagoscopy, Foreign body, Laryngoscopy, Metallic body, Stridor.

Otorhinolaryngology Clinics: An International Journal (2019): 10.5005/jp-journals-10003-1313

\section{INTRODUCTION}

The most common midnight emergency in pediatric otolaryngology remains to be a foreign body $(\mathrm{FB})$ in the airway followed by in the esophagus. It is a significant cause of mortality and morbidity especially in small children in whom the protective laryngeal reflexes are still not well developed along with incomplete dentition. ${ }^{1}$ In these cases, it's very important to act fast and remove the FB swiftly and safely before any complications arise. Although most FBs are discovered soon after ingestion or aspiration, there have been reports where FBs have remained neglected for long time and caused morbidity in those harboring them and sometimes can be missed on routine imaging. Foreign bodies of the esophagus pass through commonly but sometimes are lodged in the cricopharynx and pose a threat to the well-being of children. ${ }^{2}$

Children are curious by nature and tend to put every new object in their mouth from where it can travel down to either the food pipe or the airway. According to reports, in the United States, about 7\% of deaths in children below 4 years of age in 1986 were due to FB mainly of airways. Even with advancements in emergency care, it is estimated that still about 1,000 children die annually in the United States as a result of airway FBs. ${ }^{1}$ There is no substantial data present about this in India where majority of such cases go unreported due to socioeconomic factors and lack of systemic studies apart from isolated case studies.

Commonly encountered FBs in food passage are coins, pencil tips, marvels, and small toys but sometimes dentures and alkaline batteries as well. Common things seen for the airway are peanut pieces, peas, and rarely metallic bodies. Paroxysms of coughing after an episode of unsupervised play, siblings trying to feed each other or playing together, and a child suddenly showing distress even when around the caretaker should raise suspicion of a FB and should be dealt with urgency. Laryngotracheal FBs though less common than bronchial FBs are important in case of very small children. Lower airway FBs produce symptoms early but laryngeal FBs do not raise same amount of urgency with subdued symptoms. When the history is doubtful or absent, chest and airway radiology sometimes supplemented with fluoroscopy helps in the correct diagnosis. ${ }^{1}$ Sometimes, even the CT scan is used
${ }^{1-3}$ Department of ENT and Head and Neck Surgery, SRMS Institute of Medical Sciences, Bareilly, Uttar Pradesh, India

Corresponding Author: Amit K Rana, Department of ENT and Head and Neck Surgery, SRMS Institute of MEdical Sciences, Bareilly, Uttar Pradesh, India, Phone: +91 9760718181, e-mail: dr.akrana@gmail.com

How to cite this article: Sharma VK, Rana AK, Sharma R. Uncommon and Dangerous Foreign Body in an Infant's Larynx: An Interesting Presentation. Int J Otorhinolaryngol Clin 2019;11(2):49-51.

Source of support: Nil

Conflict of interest: None

to make a confirmed diagnosis when conventional radiological investigations fail.

\section{Case Description}

We report a case of an 8-month-old female patient who was admitted to the Emergency Department of SRMS Institute of Medical Sciences, Bareilly, India, with complaint of mild difficulty in breathing and pooling of saliva with inability to take oral feeds since last 8 hours. Although a clear history was not elicited, suspicion of FB was raised as the last information provided was that the child was playing near her mother with family getting ready for a function in the local community and then started coughing intermittently, refused feeds, and the symptoms persisted throughout the function. The patient was crying excessively and looked exhausted. Examination showed mild respiratory distress, biphasic stridor, gurgling sounds during inspiration and expiration, and continuous dribbling of saliva from angle of the mouth.

The child refused to take even the liquid feed. $\mathrm{SpO}_{2}$ was $87-94 \%$ without oxygen support. On auscultation, added sounds were present with equal air entry bilaterally. The patient was kept on oxygen and an urgent skiagram soft tissue neck, chest AP and lateral view was ordered. X-ray showed a flat broad ring with sharp pointed ends like radiopaque shadow at the level of C4-C6 (Figs 1 and 2).

Urgent direct laryngoscopy (Chevalier Jackson laryngoscope) was done under general anesthesia and a metallic ring was seen 


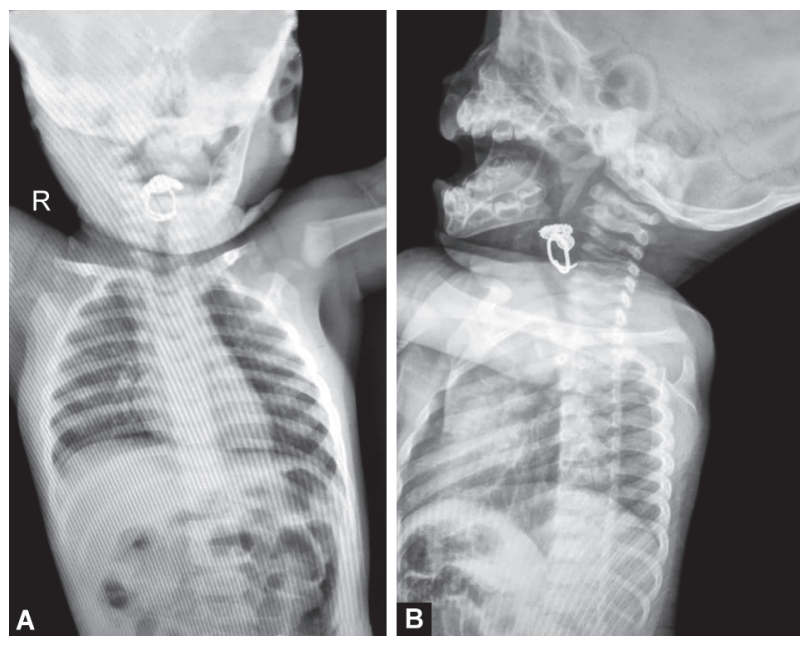

Figs $1 \mathrm{~A}$ and $\mathrm{B}$ : $\mathrm{X}$-ray neck and chest: (A) AP view; (B) Lateral view

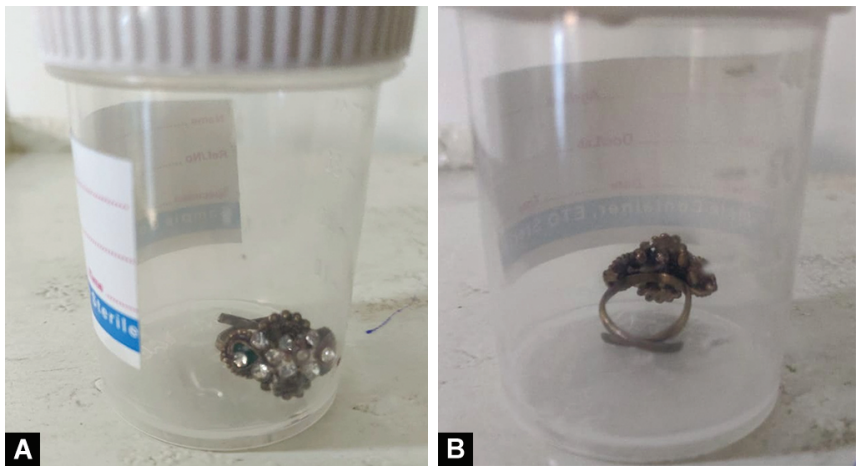

Figs $3 \mathrm{~A}$ and $\mathrm{B}$ : Foreign body-Bichhia

with a upper flat part over arytenoids covering the posterior half of the glottis opening and the circular ring with sharp ends inside the cricopharynx. This was a unique presentation as due to the narrow laryngopharynx of a small child and large size of the metallic $F B$, openings of both the food pipe and the airway were getting blocked by a single FB.

The ring, though close-ended, had overlapping sharp ends, which made its removal tricky with limited visualization because of the relatively larger size of FB and possibility of its end impacted in mucosa. The FB was removed carefully with serrated crocodile forceps after repeated suction. Further, the airway and the cricopharynx were inspected for any additional FBs. Secretions were cleared from the airway. The patient was kept under observation for next 12 hours, which showed immediate improvement of symptoms. The patient resumed oral feeds and had normal oxygen levels without any support. Prophylactic nebulization with asthalin and adrenaline was given 4 hourly and a shot of antibiotic was given before discharging the patient.

Retrospectively, history revealed that the FB was a missing silver toe ring (Bichhia) of the mother, which the child may have accidentally put in mouth while the mother was busy getting ready for the function. The patient was unable to cough it out as the ring was lodged into the cricopharynx with the sharp ends and the upper horizontal part was covering the glottis opening, which causes the respiratory distress (Fig. 3).

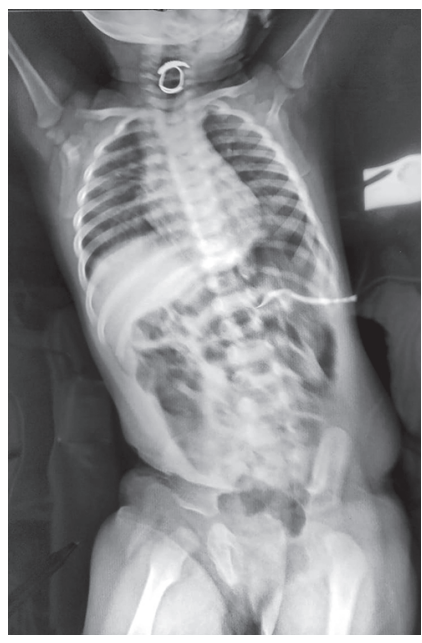

Fig. 2: X-ray neck, chest and abdomen (AP view)

\section{Discussion}

Majority of FB aspirations are seen from 1 year to 5 years of age as at this age children are curious and trying to interact with the surroundings in their own way. Most cases of FB aspirations below 1 year result due to an elder sibling playing with the baby and trying to feed something. Foreign body ingestion or aspiration in children may present with a wide variety of symptoms; sometimes it can be misdiagnosed and the patient may go unattended for long times. Not many laryngeal bodies are reported or suspected as most pass into bronchus or are coughed out. $\mathrm{Lima}^{3}$ as well as Kent and Watson reported only few laryngeal FBs in their study. ${ }^{4}$ Same was documented by Rothman who saw only 5 cases out of a series of 225 patients. Sometimes such laryngeal FBs can result in respiratory obstruction and reflex laryngospasm. ${ }^{5}$

Metallic FBs in larynx are even rare. Mostly metallic wires and safety pins are discovered. We also have encountered ball pen caps and coat buttons getting stuck in the larynx. Bakshi reported two cases in which one had a metallic spring buried in the supraglottic region. ${ }^{6}$ Similarly, Mundra reported a metallic FB in between the vocal cords of a 6-month-old child pushed in her mouth by her elder brother. For the diagnosis of FB, history examination and radiology are usually enough. Sensitivity and specificity of radiology were found to be 73 and $45 \%$, respectively, by Silvia et al. ${ }^{7}$ Sometimes even $\mathrm{CT}$ is needed to reach a correct diagnosis. ${ }^{8-11}$

Rigid bronchoscopy still remains the most effective method to tackle airway FBs. ${ }^{12-15}$ Laryngeal FBs, however, can be tackled with a direct laryngoscope especially in infants. ${ }^{16-19}$

\section{Conclusion}

Accidental FB ingestion in infants is not an uncommon incident. The FB should be removed preferably under general anesthesia at the earliest before it dislodges and may cause fatal complications. While dealing with sharp and metallic FBs, we must keep in mind the safety of mucosal walls and unnecessary trauma by sharp edges should be avoided. While dealing with FBs, tricky situations like the one we reported should be kept in mind too where a FB that was expected to be in the cricopharynx was seen to engage both the glottis opening and the cricopharynx making it tricky to remove safely. Removal of such FB requires prompt decision making and 
an experienced anesthetist so that unnecessary complications may be avoided.

\section{References}

1. Mundra RK, Agarwal R, Sinha R. Unusual foreign body aspiration in infants below 6 months of age. Indian J Otolaryngol Head Neck Surg Apr-Jun 2014;66(2):145-148. DOI: 10.1007/s12070-013-0668-0.

2. Şentürk $E$, Şen $S$. An unusual case of foreign body aspiration and review of the literature.. Tüberküloz ve Toraks Dergisi 2011;59(2): 173-177. DOI: 10.5578/tt.2134.

3. Kent SE, Watson MG. Laryngeal foreign bodies. J Laryngol Otol 1990;104:131-133. DOI: 10.1017/S0022215100112058.

4. Lima JA. Laryngeal foreign bodies in children: a persistent life threatening problem. Laryngoscope 1989;99:415-420. DOI: 10.1288/00005537-198904000-00011.

5. Rothman BF, Boeckman CR. Foreign bodies in the larynx and tracheobronchial tree in children. A review of 225 cases. Ann Otol Rhinol Laryngol 1980;89:434-436. DOI: 10.1177/000348948008900512.

6. Bakshi J, Mann SBS, Gupta AK. Unusual presentation of laryngeal foreign bodies- report of two rare cases. Indian J Otolaryngol Head Neck Surg Jul-Sep 2007;59:252-254. DOI: 10.1007/s12070-007-0072-8.

7. Silvia AB, Muntz HR, Clary R. Utility of conventional radiography in the diagnosis and management of pediatric airway foreign bodies. Ann Otol Rhinol Laryngol 1998;107:834-838. DOI: 10.1177/000348949810701004.

8. Midulla F, Guidi R, Barbato A, et al. Foreign body aspiration in children. Pediatr Int 2005;47:663-668. DOI: 10.1111/j.1442-200x.2005.02136.x.

9. Steen KH, Zimmermann TH. Tracheobronchial aspirated of foreign bodies in children: a study of 94 cases. Laryngoscope
1990;100:525-530. DOI: 10.1288/00005537-19900500000016.

10. Ciftci A, Bingol-Kologlu M, Senocak ME, et al. Bronchoscopy for evaluation of foreign body aspiration in children. J Ped Surg 2003;38:1170-1176. DOI: 10.1016/S0022-3468(03)00263-X.

11. Friedman EM. Tracheobronchial foreign bodies. Otolaryngol Clin North Am 2000;33:179-185. DOI: 10.1016/S0030-6665(05)70214-0.

12. Black RE, Choi KJ, Syme WC, et al. Bronchoscopic removal of aspirated foreign bodies in children. Am J Surg 1984;148:778-781. DOI: 10.1016/0002-9610(84)90436-7.

13. Manto PC, Tuggle DW, Tunell WP. An appropriate negative bronchoscopy rate in suspected foreign body aspiration. Am J Surg 1989;158:622-664. DOI: 10.1016/0002-9610(89)90208-0.

14. Marquette $\mathrm{CH}$, Martinot $\mathrm{A}$. Foreign body removal in adults and children. In: Bolliger CT. Interventional Bronchoscopy. Basel: S. Karger AG; 2000. pp. 96-107.

15. Baharloo F, Veyckemans F, Francis C. Tracheobronchial foreign bodies presentation and management in children and adults. Chest 1999;115:1357-1362. DOI: 10.1378/chest.85.3.452c.

16. Nakhosteen JA. Tracheobronchial foreign bodies. Eur Respir J 1994;7:429-430. DOI: 10.1183/09031936.94.07030429.

17. Swanson KL, Prakash UBS, Midthun DE. Flexible bronchoscopic management of airway foreign bodies in children. Chest 2002;121:1695-1700. DOI: 10.1378/chest.121.5.1695.

18. Chen $\mathrm{CH}$, Lai CL, Tsai TT, et al. Foreign body aspiration into the lower airway in Chinese adults. Chest 1997;112:129-133. DOI: 10.1378/ chest.112.1.129.

19. Uzaslan E, Ursavas A, Ediger D, et al. An unusual way of tracheal stoma cleaning could end up with foreign body aspiration in a laryngectomized patient. Tuberk Toraks 2005;53:61-64. 